Revista Brasileira de Farmacognosia Brazilian Journal of Pharmacognosy 22(3): 642-648, May/Jun. 2012

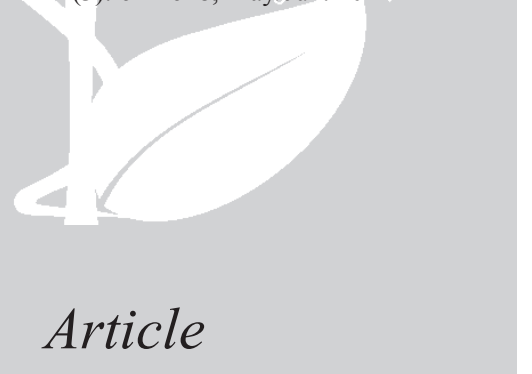

Received 15 Jul 2011

Accepted 1 Nov 2011

Available online 31 Jan 2012

Keywords:

isolation

oryzanol

hyperlipidemia

rats

rice bran oil

Triton WR-1339

ISSN 0102-695X

http://dx.doi.org/10.1590/S0102-

$695 \times 2012005000023$

\section{Anti-hyperlipidemic activity of oryzanol, isolated from crude rice bran oil, on Triton WR-1339-induced acute hyperlipidemia in rats}

\author{
Somsuvra B. Ghatak, Shital J. Panchal* \\ Department of Pharmacology, Institute of Pharmacy, Nirma University, India.
}

\begin{abstract}
Experimental studies carried out for evaluating the anti-hyperlipidemic properties of rice bran components have given interesting but often contrasting results. Therefore, the current study was initiated to investigate the anti-hyperlipidemic activity of oryzanol (OZ), a commercially-important bioactive phytochemical, isolated from crude rice bran oil (cRBO). OZ was isolated by a two-step solvent crystallization process from cRBO, which was extracted from fresh rice bran by hexane mediated soxhlet extraction. Subsequently, OZ (50 and $100 \mathrm{mg} / \mathrm{kg}$, p.o.) was evaluated for anti-hyperlipidemic activity in Triton WR-1339-induced acute hyperlipidemic albino rats by estimating serum triacylglyceride (TG), total cholesterol (TC), very low density lipoproteincholesterol (VLDL-C), low-density lipoprotein-cholesterol (LDL-C) and high-density lipoprotein-cholesterol (HDL-C) levels with atorvastatin as the reference standard. The degree of protection was also assessed by measuring the levels of various hepatic antioxidant enzymes. OZ evoked a significant decrease in the levels of serum cholesterol, triacylglycerides, LDL, VLDL and a significant increase in the level of serum HDL and hepatic anti-oxidant enzymes. It also showed a significant ameliorative action on elevated atherogenic index (AI) and LDL/HDL-C ratios. These findings indicate that $\mathrm{OZ}$ possesses the potential to lower plasma lipid concentrations and might be of therapeutic benefit in hyperlipidemia and atherosclerosis.
\end{abstract}

\section{Introduction}

Experimental and epidemiological studies have suggested that hyperlipidemia is a highly predictive risk factor for atherosclerosis, coronary artery disease (CAD), and cerebral vascular diseases, the primary causes of mortality in the developing countries like India (Ghatak \& Asthana, 1995). The allopathic hypolipidemic drugs, although available at large in the market, their popularity has been marred by numerous side effects, severe contraindications and exuberant cost and this has further necessitated the search for alternatives (Speight, 1987). Furthermore, published reports have ascertained the isolation of certain nutrients that can be used as dietary supplements to meet up with the dietary imbalances in order to reduce the cardiovascular disease risk associated with hyperlipidemia (Cicero \& Derosa, 2005). For instance, there are ample evidences elucidating the antihypercholesterolemic effect of fixed oils that are rich in polyunsaturated fatty acids, especially linolenic and linoleic acid.

It is in this context of developing alternative, effective and better anti-hyperlipidemic drugs for the prevention of cardiovascular diseases, that a global interest has been generated in recent years pertaining to the beneficial nutritive effects of bioactive phytochemicals like OZ, obtained from crude rice bran oil (cRBO) (Cicero \& Gaddi, 2001).

RBO has been the focus of surmount attention because of its balanced fatty acid profile and rich source of bioactive phytoceuticals such as, OZ, tocopherols, phytic acid, lecithin, inositol, waxes etc. OZ is an important natural constituent of cRBO with its content ranging from 1.5 to $2.9 \%$ (Seetharamaiah \& Prabhakar, 1986). Its fundamental molecular structure is the ferulic acid aromatic phenolic nucleus esterified to cyclopentanperihydrophenanthrene. OZ, althoughinitially presumed to be a single component, it was shown to be a mixture of ferulic acid (4-hydroxo-3-methoxycinnamic acid) ester with phytosterol or triterpene alcohols. Major portions of OZ include cycloartenyl ferulate, 24methylene cycloartanyl ferulate and campesteryl ferulate (Metwally et al., 1974). OZ is an anti-oxidant compound that has been associated with decreasing platelet aggregation, increasing the muscle mass and treating nerve imbalances and the disorders of menopause. It has 
also been shown to exhibit anti-aging effect similar to tocopherols, anti-dandruff and anti-itching properties and to cause an improvement of capillary action of blood vessels (Patel \& Naik, 2004).

In the last couple of decades, numerous studies have been carried out to elucidate the effect of RBO and $\mathrm{OZ}$ activity on lipid metabolism and oxidation in rats, rabbits, hamsters, monkeys and humans. While most of these studies have confirmed the $\mathrm{OZ}$ component of RBO to be responsible for the cholesterol lowering property in chronic hyperlipidemia models using high fat diet, the studies carried out on the rats have yielded interesting but often contrasting results (Cicero \& Derosa, 2005). Furthermore, there is paucity of reports on the potential effects of $\mathrm{OZ}$ on acute hyperlipidemia using Triton WR1339, a non-ionic detergent (oxyethylated tertiary octyl phenol formaldehyde polymer) that has been widely used to produce acute hyperlipidemia in animal models in order to screen natural or chemical drugs and to study cholesterol and triacylglycerol metabolism (Zeniya \& Reuben, 1988).

In light of the above perspective, the current investigation was carried to assess the anti-hyperlipidemic activity of OZ in triton WR-1339-induced acute hyperlipidemia in rats.

\section{Materials and methods}

\section{Drugs and chemicals}

Rice bran was procured from Suryodaya Rice Mills, Ahmedabad, Gujarat through their milling process. Triton WR-1339 was purchased from Sigma-Aldrich Chemie GMBH. Atorvastatin calcium was obtained as a gift sample from Troikaa Pharmaceuticals Limited, India. Thiobarbituric acid was purchased from Spectrochem Pvt. Ltd., India. All diagnostic kits were purchased from Lab Care Diagnostics Pvt. Ltd., India. All solvents and reagents were either of HPLC grade or of analytical reagent grade and were obtained from commercial sources.

\section{Extraction of $R B O$}

Fresh rice bran obtained from the local rice mill was stored in a refrigerator before use. Crude RBO was extracted from rice bran $(50 \mathrm{~g})$ by soxhlet extraction for $3 \mathrm{~h}$ using hexane as the solvent. The extracted crude oil was stored at $-5{ }^{\circ} \mathrm{C}$ and subsequently analyzed for the various physicochemical parameters, such as organoleptic characters, specific gravity, viscosiiy, moisture content, saponification value, unsaponifiable matter, wax content, iodine value, acetyl value, acid value, hydroxyl value, ester value and peroxide value using various standard official methods, the results of which have already been published previously (Ghatak \& Panchal, 2010).

\section{Isolation of $O Z$ from $c R B O$}

The isolation of OZ from cRBO was achieved by a two-step crystallization process previously described by Zullaikah et al. (2009) with some modifications. In the first step of isolation, the OZ-rich product was concentrated in the liquid phase by solvent crystallization using methanol/acetone $(7: 3, \mathrm{v} / \mathrm{v})$. In the second step, the OZ-rich product was kept at ambient temperature for $24 \mathrm{~h}$. After that, hexane was added as an anti-solvent and kept at $5 \pm 1{ }^{\circ} \mathrm{C}$ for $48 \mathrm{~h}$. Under optimal operational conditions, supplemented by considerable savings of both time and solvents, white OZ crystals with a purity of $94.07 \%$ and recovery of $55.61 \%$ were obtained.

\section{Experimental animals}

Adult wistar rats of either sex weighing 250$300 \mathrm{~g}$ were procured from the central animal facility of the Institute of Pharmacy, Nirma University, Ahmedabad. The animals were maintained at controlled temperature as well as humidity and fed with standard diet and water provided ad libitum. The experimental protocol was approved by Institutional Animal Ethics Committee (IAEC) of Institute of Pharmacy, Nirma University, as per the guidance of committee for the purpose of Control and Supervision of Experiments on Animals (CPCSEA), Ministry of Social Justice and Empowerment, Government of India. Test doses of $\mathrm{OZ}$ were selected for rats (50 and $100 \mathrm{mg} / \mathrm{kg} \mathrm{b.} \mathrm{w.,} \mathrm{p.o.)}$ based on the published literature reports (Sakamoto et al., 1987; Nakayama et al., 1987).

\section{Treatment protocols}

Rats $(n=36)$ were randomized into the following groups:

1) Normal Control (NC): Received no treatment.

2) Vehicle Control (VC): Administered with 4\% Tween80 solution per day for 21 days.

3) Triton WR 1339 treated group (TRIT-C): 4\% Tween80 solution per day for 21 days and on the $21^{\text {st }}$ day intraperitoneal injection of Triton WR $1339(400 \mathrm{mg} / \mathrm{kg}$ in saline) was given.

4) Oryzanol $50 \mathrm{mg} / \mathrm{kg}+$ Triton WR 1339 (OZ-50): Oryzanol $50 \mathrm{mg} / \mathrm{kg} / \mathrm{day}$, p.o in $4 \%$ Tween-80 solution was administered for 21 days and on the $21^{\text {st }}$ day intraperitoneal injection of triton WR $1339(400 \mathrm{mg} / \mathrm{kg}$ in saline) in saline was given.

5) Oryzanol $100 \mathrm{mg} / \mathrm{kg}+$ Triton WR 1339 (OZ-100): Oryzanol $100 \mathrm{mg} / \mathrm{kg} /$ day, p.o in $4 \%$ Tween- 80 solution was administered for 21 days and on the $21^{\text {st }}$ day intraperitoneal injection of triton WR $1339(400 \mathrm{mg} / \mathrm{kg}$ in 
saline) in saline was given.

6) Atorvastatin $2 \mathrm{mg} / \mathrm{kg}+$ Triton WR 1339 (Ator): Atorvastatin $(2 \mathrm{mg} / \mathrm{kg} /$ day, orally in $0.5 \% \mathrm{CMC}$ ) was administered for 21 days and on $21^{\text {st }}$ day intra-peritoneal injection of triton WR 1339 (400 mg/ $\mathrm{kg}$ in saline) was given.

After $24 \mathrm{~h}$ of triton injection or in case of control after $24 \mathrm{~h}$ of vehicle or drug treatment, blood samples were collected from the retro-orbital plexus of rat.

\section{Estimation of biochemical parameters}

\section{Collection of serum}

The blood samples were withdrawn from retroorbital plexus under light ether anesthesia without any anticoagulant and allowed to clot for $10 \mathrm{~min}$ at room temperature. It was centrifuged at $2500 \mathrm{x}$ g for $20 \mathrm{~min}$. The serum obtained was kept at $4{ }^{\circ} \mathrm{C}$ until used.

\section{Isolation of liver}

All the animals were euthanasiously sacrificed by cervical dislocation. Liver was collected and was blotted free of blood and tissue fluids. Then it was weighed on balance and the relative weight was calculated.

Preparation of the tissue homogenate for enzyme assay

Liver, kept in cold conditions (pre-cooled in inverted petridish on ice) was removed. It was cross chopped with surgical scalpel into fine slices and was chilled in the cold $0.25 \mathrm{M}$ sucrose, quickly blotted on a filter paper. The tissue was minced and homogenized in $10 \mathrm{mM}$ Tris-HCl buffer, $\mathrm{pH} 7.4(10 \%$ w/v) with 25 strokes of tight teflon pestle of glass homogenizer at a speed of $2500 \mathrm{x}$ g. The clear supernatant was used for other enzymes assays.

\section{Parameters assessed in serum}

In vitro quantitative determinations of the activity of TC, TG, LDL-C, HDL-C concentration in serum were carried out using standard enzymatic kits (Lab Care Diagnostics, India). The concentration of VLDL-C was estimated as per the method proposed by Russell et al. (1990). Various other coronary disease risk factors such as atherogenic index (A.I.), HDL ratio and LDL-C/HDL-C ratio were also evaluated as per previously reported methods (Sheela \& Augusti; 1995; Sharma et al., 1995).

Parameters assessed in the liver homogenate
The activities of anti-oxidant enzymes like reduced glutathione and the extent of lipid peroxidation were assayed in the liver homogenate as per previously established methods (Moron et al., 1979; Ohkawa et al., 1979; Lowry et al., 1951).

\section{Statistical analysis}

All the values are expressed as mean \pm SEM. Statistics was applied using Graph Pad Prism version 5.0 for Windows, Graph Pad software, San Diego, California, USA. One way ANOVA followed by Tukey's multiple comparison test was used to determine the statistical significance between various groups. Differences were considered to be statistically significant when $\mathrm{p}<0.05$.

\section{Results}

\section{Effects on serum lipid profile}

The normal control and vehicle control animals showed nearly similar lipid profile. Treatment with triton WR 1339 showed a significant increase in serum TC, LDL-C, TG and VLDL-C when compared to the normal control animals. A significant decrease in HDL-C was observed in the triton WR 1339 control animals. A dose dependant reduction in the levels of TC, TG, LDL-C and VLDL-C was observed with $50 \mathrm{mg} / \mathrm{kg}$ and $100 \mathrm{mg} / \mathrm{kg}$ dose of OZ. A significant increase in HDL-C levels was seen in the animals pretreated with $100 \mathrm{mg} / \mathrm{kg}$ /day of OZ (Figure 1).

Effects on atherogenic index, $H D L-C$ ratio and $L D L-C /$ $H D L-C$ ratio (Coronary disease risk factors)

Atherogenic index (A.I.), an indicator of the deposition of foam cells or plaque or fatty infiltration or lipids in aorta and liver, was found to be higher in the Triton WR 1339 group as compared to the normal and vehicle control group. Other coronary disease risk predictor indices such as HDL ratio and LDL-C/HDL-C in the Triton WR 1339 group respectively lower and higher as compared to the groups pre-treated with $\mathrm{OZ}$ (Table 1).

\section{Effects on lipid peroxidation and anti-oxidant enzyme} level

Malondialdehyde level was measured as an index of lipid peroxidation in the liver homogenate. Triton WR 1339 controlled animals showed a malondialdehyde (MDA) level (nmol/mg protein) significantly higher than that observed in normal and vehicle control groups. Atorvastatin $2 \mathrm{mg} / \mathrm{kg}$ and $\mathrm{OZ} 50$ and $100 \mathrm{mg} /$ $\mathrm{kg}$ significantly reduced the MDA level. A remarkable 
A

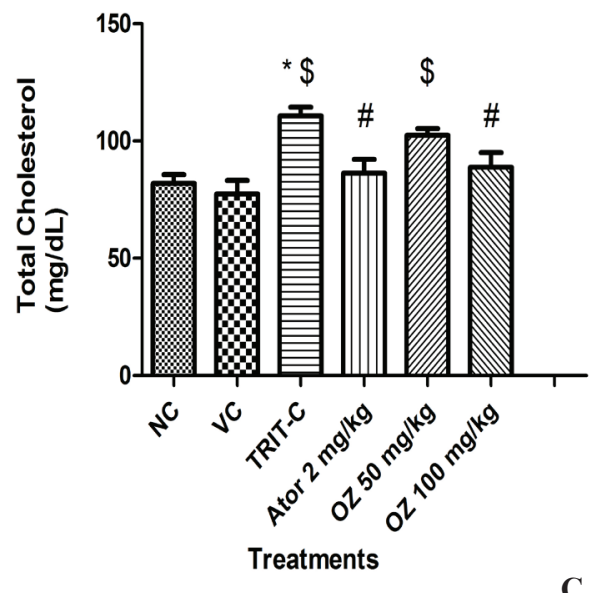

C

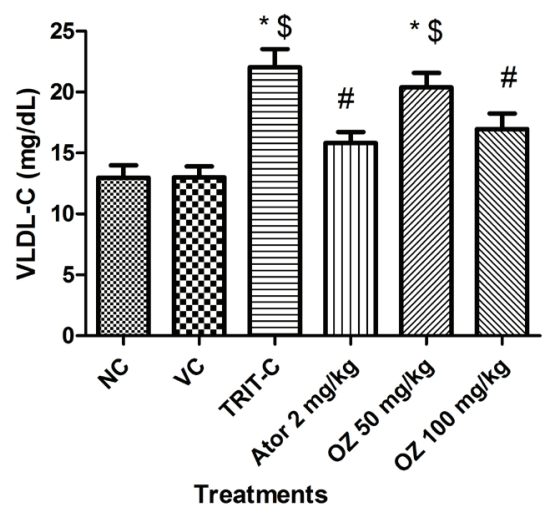

B

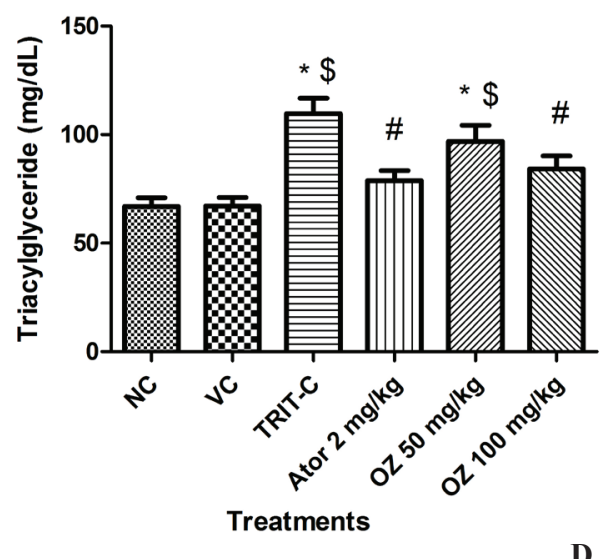

D

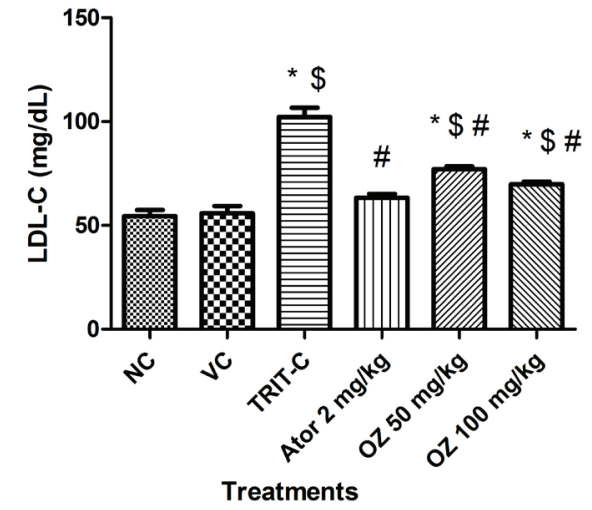

$\mathbf{E}$

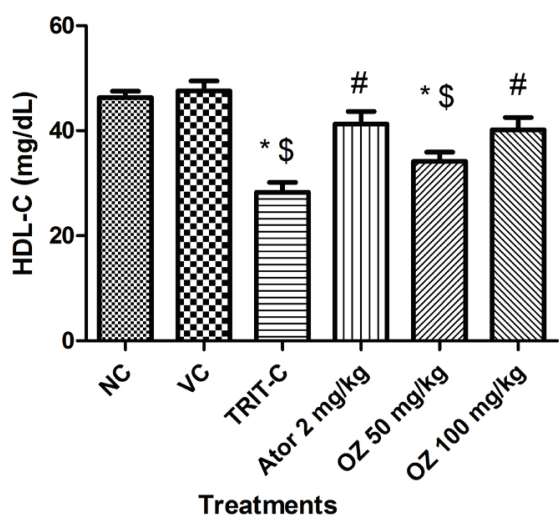

Figure 1. Effect of oryzanol pre-treatment on (a) total cholesterol levels (b) triacylglyceride levels (c) very low density lipoprotein cholesterol (VLDL-C) levels (d) low density lipoprotein cholesterol (LDL-C) levels and (e) high density lipoprotein cholesterol (HDL-C) levels; $\mathrm{n}=6$; Values are expressed in mean \pm SEM; NC: Normal control (no treatment); VC: Vehicle control (4\% Tween80), orally per day for 21 days; TRIT-C: 4\% Tween-80 solution per day for 21 days+Triton WR 1339 (400 mg/kg), single i.p. injection on the $21^{\text {st }}$ day; OZ $50 \mathrm{mg} / \mathrm{kg}$ : Oryzanol $(50 \mathrm{mg} / \mathrm{kg})$, orally per day for 21 days+Triton WR 1339 (400 mg/kg), single i.p. injection on the $21^{\text {st }}$ day; OZ $100 \mathrm{mg} / \mathrm{kg}$ : Oryzanol $(100 \mathrm{mg} / \mathrm{kg})$, orally per day for 21 days+Triton WR 1339 (400 mg/kg), single i.p. injection on the $21^{\text {st }}$ day; Ator: Atorvastatin $(2 \mathrm{mg} / \mathrm{kg})$, orally per day for 21 days+Triton WR 1339 (400 mg/kg), single i.p. injection on the $21^{\text {st }}$ day. ${ }^{*} p<0.05$ versus NC, ${ }^{\mathrm{s}} p<0.05$ versus VC, ${ }^{\#} p<0.05$ versus TRIT-C; Values are obtained by one way ANOVA followed by Tukey's multiple comparison test. 
depression was seen in the levels of antioxidant enzymereduced glutathione $(\mu \mathrm{g} / \mathrm{mg}$ protein) in the triton WR 1339 treated group as compared to the normal control. Pre-treatment with OZ $50 \mathrm{mg} / \mathrm{kg}$ and $100 \mathrm{mg} / \mathrm{kg}$ showed a significant dose-dependent increase in the levels of reduced glutathione (Figure 2).

Table 1. Effect of oryzanol pre-treatment on atherogenic index, high density lipoprotein cholesterol (HDL-C) ratio and low density lipoprotein cholesterol/high density lipoprotein cholesterol (LDL-C/HDL-C) ratio.

\begin{tabular}{lccc}
\hline \multirow{2}{*}{ Groups } & \multicolumn{3}{c}{ Parameters } \\
\cline { 2 - 4 } & $\begin{array}{c}\text { Atherogenic } \\
\text { Index (A.I.) }\end{array}$ & HDL Ratio & LDL-C / HDL-C \\
\hline $\mathrm{C}$ & 0.767 & 0.565 & 1.196 \\
VC & 0.628 & 0.614 & 1.173 \\
TRIT-C & $2.913^{* \mathrm{~s}}$ & 0.255 & 3.612 \\
Ator $2 \mathrm{mg} / \mathrm{kg}$ & $1.088^{\#}$ & 0.478 & $1.533^{\#}$ \\
OZ $50 \mathrm{mg} / \mathrm{kg}$ & 1.999 & 0.333 & 2.256 \\
OZ $100 \mathrm{mg} / \mathrm{kg}$ & $1.209^{\#}$ & 0.452 & $1.737^{\sharp}$ \\
\hline
\end{tabular}

$\mathrm{n}=6$; Values are expressed in mean \pm SEM; NC: Normal control (no treatment); VC: Vehicle control (4\% Tween-80), orally per day for 21 days; TRIT-C: $4 \%$ Tween- 80 solution per day for 21 days+Triton WR 1339 (400 mg/kg), single i.p. injection on the $21^{\text {st }}$ day; OZ $50 \mathrm{mg} / \mathrm{kg}$ : Oryzanol $(50 \mathrm{mg} / \mathrm{kg})$, orally per day for 21 days+Triton WR 1339 (400 $\mathrm{mg} / \mathrm{kg}$ ), single i.p. injection on the $21^{\text {st }}$ day; OZ $100 \mathrm{mg} / \mathrm{kg}$ : Oryzanol $(100 \mathrm{mg} / \mathrm{kg})$, orally per day for 21 days+Triton WR 1339 (400 mg/kg), single i.p. injection on the $21 \mathrm{st}$ day; Ator: Atorvastatin $(2 \mathrm{mg} / \mathrm{kg})$, orally per day for 21 days+Triton WR $1339(400 \mathrm{mg} / \mathrm{kg})$, single i.p. injection on the 21 st day. ${ }^{*} p<0.05$ versus $\mathrm{NC},{ }^{s} p<0.05$ versus $\mathrm{VC},{ }^{*} p<0.05$ versus TRIT-C; Values are obtained by one way ANOVA followed by Tukey's multiple comparison test.

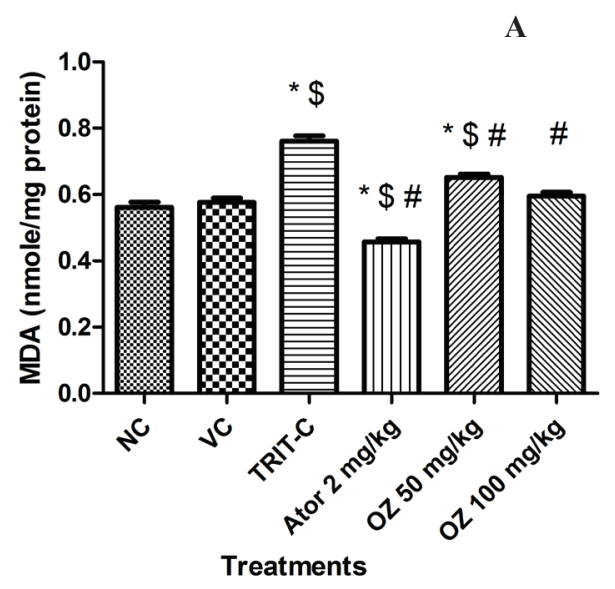

\section{Discussion}

There are ample scientific evidences to demonstrate the hypocholesterolemic effects of rice bran in experimental animals and humans in long term experimental models of hyperlipidemia, induced by high fat diet. Such effects may be attributed to the unsaponifiable fraction of rice bran oil, primarily phytosterol, tocols (tocopherols and tocotrienols), OZ, triterpene alcohol and other minor compounds (Sharma \& Rukmini, 1986). Although the exact mechanism of action of rice bran and the derived oil on lipid metabolism is not completely evident as yet, the possible fundamental antiatherosclerotic role rests on OZ (Kanbara et al., 1992).

The reduction of TC by OZ was associated with a decrease in its LDL fraction, which is a potentially modifiable risk factor of cardiovascular diseases and the target of several hypocholesterolemic therapies. The findings of the present study suggest that cholesterollowering activity of $\mathrm{OZ}$ can result from the enhanced catabolism of LDL-C through hepatic receptors for final elimination in the form of bile acids (Khanna et al., 2002).

Increased levels of HDL after administration of $\mathrm{OZ}$ indicated its potent protective action against atherogenesis since an independent inverse relationship between blood HDL-C levels and cardiovascular risk incidence has been documented widely (Malloy \& Kan, 1994). The underlying mechanism may be attributed to the enhancement of lecithin cholesteryl acyl transferase (LCAT), which plays a key role in incorporating the free cholesterol into HDL and transferring back to VLDL

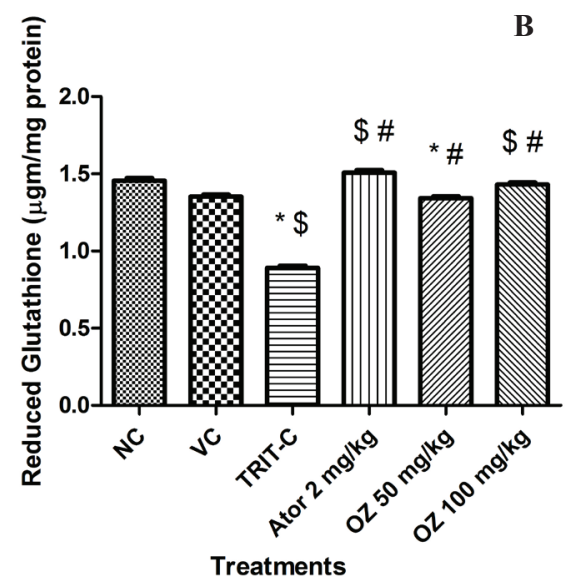

Figure 2. Effect of oryzanol pre-treatment on A. lipid peroxidation (malondialdehyde level); B. anti-oxidant enzyme level (reduced glutathione) $\mathrm{n}=6$; Values are expressed in mean \pm SEM; NC: Normal control (no treatment); VC: Vehicle control (4\% Tween80), orally per day for 21 days; TRIT-C: 4\% Tween-80 solution per day for 21 days+Triton WR 1339 (400 mg/kg), single i.p. injection on the $21^{\text {st }}$ day; OZ $50 \mathrm{mg} / \mathrm{kg}$ : Oryzanol $(50 \mathrm{mg} / \mathrm{kg})$, orally per day for 21 days+Triton WR $1339(400 \mathrm{mg} / \mathrm{kg})$, single i.p. injection on the $21^{\text {st }}$ day; OZ $100 \mathrm{mg} / \mathrm{kg}$ : Oryzanol $(100 \mathrm{mg} / \mathrm{kg})$, orally per day for 21 days+Triton WR 1339 (400 mg/kg), single i.p. injection on the $21^{\text {st }}$ day; Ator: Atorvastatin $(2 \mathrm{mg} / \mathrm{kg})$, orally per day for 21 days+Triton WR 1339 (400 mg/kg), single i.p. injection on the $21^{\text {st }}$ day. ${ }^{*} p<0.05$ versus $\mathrm{NC},{ }^{\$} p<0.05$ versus VC, ${ }^{*} p<0.05$ versus TRIT-C; Values are obtained by one way ANOVA followed by Tukey's multiple comparison test. 
or Intermediate Density Lipoproteins (IDL), which is taken back by the liver cells (Devi \& Sharma, 2004). Additional mechanism may involve an inhibition of hepatic triglyceride lipase (HTL) on HDL which may lead to a rapid catabolism of blood lipids through extrahepatic tissues (Anila \&Vijayalakshmi, 2002).

Moreover, OZ at the dose of $100 \mathrm{mg} / \mathrm{kg} /$ day; p.o. significantly suppressed the elevated levels of TG, thereby suggesting that $\mathrm{OZ}$ is able to restore, at least partially, the catabolism of triacylglycerides.

Administration of $\mathrm{OZ}$ provides a beneficial effect on lipid metabolism in regard to the reduction of AI. In fact, the AI was decreased in all the treated groups, with a significant reduction being observed in the $\mathrm{OZ} 100 \mathrm{mg} /$ $\mathrm{kg} /$ day, p.o. and atorvastatin $2 \mathrm{mg} / \mathrm{kg}$, p.o. treated group. Similar results have been reported while investigating the hypolipidemic effect of other natural products (Cherng \& Shih, 2005). Such an ameliorative action may be attributed to the lipid-lowering property of OZ.

Furthermore, there exists a positive correlation between an increased LDL-C/HDL-C ratio and the development of atherosclerosis. Again, the administration of OZ $100 \mathrm{mg} / \mathrm{kg} /$ day, p.o. and atorvastatin $2 \mathrm{mg} / \mathrm{kg}$, p.o. significantly suppressed the higher values of LDL-C/ HDL-C ratio elucidating the beneficial effect of $\mathrm{OZ}$ in preventing atherosclerosis incidence.

Oxidative stress is one of the prominent causative factors for hyperlipidemia (Lee et al., 2002). Increased lipid peroxidation is thought to be a consequence of oxidative stress due to impairment in the dynamic balance between pro-oxidant and antioxidant mechanism, resulting in the formation of free radicals, the natural byproducts of many oxidative metabolic processes within cells causing damage to cell walls, certain cell structures and genetic material within the cells. Our study indicated that circulating concentration of MDA in the triton induced group was significantly higher than the control as well as the vehicle control group, indicating increasing oxidative stress with hyperlipidemia. These increased levels could be attributed to increased reactive oxygen species (ROS) production and/or deficiency of antioxidant defense system. Similarly, decreased activities of reduced glutathione, one of the first lines of cellular defense against oxidative injury, had been observed in the triton induced group. Thus, insufficient detoxification of these reactive oxygen species by antioxidant enzymes may lead to an occurrence of imbalance between antioxidant and oxidant systems. Low reduced glutathione activity could also attribute to enzyme inactivation by ROS bringing about damage to proteins. Interestingly, pre-treatment with $\mathrm{OZ}$ at $50 \mathrm{mg} / \mathrm{kg}$ and $100 \mathrm{mg} / \mathrm{kg}$ doses reduced the level of lipid peroxides (MDA) and increased the levels of reduced glutathione, indicating an effective anti-oxidant property of the test drug. The findings are in concordance to that reported in the literature, which indicates $\mathrm{OZ}$ to be an effective scavenger of free radicals (Xu \& Godber, 2001).

It is possible that OZ's antihypercholesterolemic effect is partially due to its sterol moiety, which is partly split off from the ferulic acid structure in the small intestine by cholesterol esterase (Swell et al., 1954). The antiatherogenic action of OZ could also be based on the inhibition of the accumulation of cholesterol-esters within the macrophages or by the modulation of cholesterol acid esterase and acyl-CoA-cholesterol-acyltransferase (Rukmini \& Raghuram, 1991).

Therefore, the findings obtained from the current study reinforce the potential anti-hyperlipidemic activity of $\mathrm{OZ}$ in an acute hyperlipidemia model in rats, which may be attributed partially to its anti-oxidant activity. The findings are encouraging for further assessment to elucidate a more detailed mechanism(s) of action on a cellular and molecular level for the anti-hyperlipidemic activity of $\mathrm{OZ}$.

\section{Acknowledgement}

The authors wish to thank the Department of Science \& Technology, New Delhi, India for providing financial assistance (INSPIRE Fellowship: JRF Professional) for carrying out this work.

\section{References}

Anila L, Vijayalakshmi NR 2002. Flavonoids from Emblica officinalis and Mangifera indica-effectiveness for dyslipidemia. J Ethnopharmacol 79: 81-87.

Cherng JY, Shih MF 2005. Preventing dyslipidemia by Chlorella pyrenoidosa in rats and hamsters after chronic high fat diet treatment. Life Sci 76: 30013013.

Cicero AFG, Derosa G 2005. Rice bran and its main components: potential role in the management of coronary risk factors. Curr Top Nutraceutical R 3: 29-46.

Cicero AFG, Gaddi A 2001. Rice Bran oil and $\gamma$-oryzanol in the treatment of hyperlipoproteinemias and other conditions. Phytother Res 15: 277-289.

Devi R, Sharma DK 2004. Hypolipidemic effect of different extracts of Clerodendron colebrookianum Walp in normal and high-fat diet fed rats. J Ethnopharmacol 90: 63-68.

Ghatak A, Asthana OP 1995. Recent trends in hyper lipoproteinemias and its pharmacotherapy. Indian $J$ Pharm 27: 14-29.

Ghatak SB, Panchal SJ 2010. Methodical characterization and quantitative estimation of crude Oryza sativa bran oil. Int J Chem Anal Sci 1: 181-185.

Kanbara R, Fukuo Y, Hada K, Hasegawa T, Terashi A 1992. The influence of sonic stress on lipid metabolism and the progress of atherosclerosis in rabbits with 
hypercholesterolemia - studies on antiaterosclerotic effect of $\gamma$-oryzanol in sonic stress. Jap J Atheroscler 20: $159-163$.

Khanna AK, Rizvi F, Chander R 2002. Lipid lowering activity of Phyllanthus niruri in hyperlipemic rats. $J$ Ethnopharmacol 82: 19-22.

Lee Mi-K, Bok SH, Jeong TS, Moon SS, Lee SE, Park YB, Choi MS 2002. Supplementation of naringenin and its synthetic derivative alters antioxidant enzyme activities of erythrocyte and liver in high cholesterol- fed rats. Bioorg Med Chem Lett 10: 2239-2244.

Lowry OH, Rosebrough NJ, Farr AL, Randall RJ 1951. Protein measurement with the Folin phenol reagent. $J$ Biol Chem 193: 265-275.

Malloy MJ, Kan JP 1994. Medical management of hyperlipidemic states. Adv Internal Med 39: 603-631.

Metwally AM, Habib AM, Khafagy SM 1974. Sterols and triterpene alcohols from rice bran oil. Planta Med 25: 68-72.

Moron MJ, Diperre JW, Mannerv KB 1979. Levels of glutathione, glutathione reductase and glutathione-Stransferase activities in rat lungs and liver. Biochim Biophys Acta 582: 67-71.

Nakayama S, Manabe A, Suzuki J, Sakamoto K, Inagaki T 1987. Comparative effects of two forms of gamma oryzanol in different sterol compositions on hyperlipidemia induced by cholesterol diet in rats. Jpn J Pharmacol 44: 135-144

Ohkawa H, Ohishi N, Yagik S 1979. Assay for lipid peroxides in animal tissues by thiobarbituric acid reaction. Anal Biochem 95: 351-358.

Patel M, Naik SN 2004. Gamma-oryzanol from rice bran oil - A review. J Sci Ind Res India 63: 569-578.

Rukmini C, Raghuram TC 1991. Nutritional and biochemical aspects of the hypolipidemic action of rice bran oil, a review. J Am Coll Nutr 10: 593-601.

Russell JC, Koeslag DG, Dolphin PJ, Amy RM 1990. Prevention of myocardial lesions in JCR: LA-corpulent rat by nifedepine. Arteriosclerosis 10: 658-664.

Sakamoto K, Tabata T, Sirasaki K, Inagaki T, Nakayama S
1987. Effects of gamma oryzanol and cycloartenol ferulic acid ester on cholesterol diet induced hyperlipidemia in rats. Jpn J Pharmacol 45: 59-65.

Seetharamaiah GS, Prabhakar JV 1986. Oryzanol content of indian rice bran oil and its extraction from soapstock, $J$ Food Sci Technol 23: 270-273.

Sharma A, Mathur R, Dixit VP 1995. Prevention of hypercholesterolemia and atherosclerosis in rabbits after supplementation of Myristica fragrans seed extract. Indian J Physiol Pharmacol 39: 407-410.

Sharma RD, Rukmini C 1986. Rice bran oil and hypocholesterolemia in rats. Lipids 21: 715-717.

Sheela CG, Augusti KT 1995. Antiperoxide effects of S-allyl cysteine sulfoxide isolated from Allium sativum Linn. and gugulipid in cholesterol fed rats. Ind J Exp Biol 33: 337-341.

Speight TM 1987. Avery's drug treatment: principles and practice of clinical pharmacology and therapeutics, Williams and Wilkins, Baltimore: $3^{\text {rd }}$ ed.

Swell L, Field H, Treadwell CR 1954. Sterol specificity of pancreatic cholesterol esterase. Proc Soc Exp Biol Med 87: 216-218.

$\mathrm{Xu} \mathrm{Z}$, Godber JS 2001. Antioxidant activities of major components of gamma-oryzanol from rice bran using a linolenic acid model. J Am Oil Chem Soc 78: 465-469.

Zeniya M, Reuben A 1988. Triton WR-1339 induced changes in serum lipids and biliary lipid secretion. Am J PhysiolGastr L 254: G346-G354.

Zullaikah S, Melwita E, Ju YH 2009. Isolation of oryzanol from crude rice bran oil. Bioresource Technol 100: 299-302.

\section{*Correspondence}

Shital J. Panchal

Department of Pharmacology, Institute of Pharmacy, Nirma University, Sarkhej-Gandhinagar Highway, Ahmedabad-382 481, Gujarat, India shital.panchal@nirmauni.ac.in

Tel: +919687626589

Fax: +91 792717241917 